\title{
Sex Pheromones of Stenotus rubrovittatus and Trigonotylus caelestialium, Two Mirid Bugs Causing Pecky Rice, and Their Application to Insect Monitoring in Japan
}

\author{
Tetsuya Yasuda and Hiroya Higuchi \\ National Agriculture and Food Research Organization, Agricultural Research Center (NARC), Tsukuba, Ibaraki 305-8666, Japan \\ Correspondence should be addressed to Tetsuya Yasuda, tyasuda@affrc.go.jp
}

Received 15 September 2011; Revised 30 November 2011; Accepted 11 December 2011

Academic Editor: Jocelyn G. Millar

Copyright (C) 2012 T. Yasuda and H. Higuchi. This is an open access article distributed under the Creative Commons Attribution License, which permits unrestricted use, distribution, and reproduction in any medium, provided the original work is properly cited.

Two mirid bugs, Stenotus rubrovittatus and Trigonotylus caelestialium (Heteroptera: Miridae), are important pests that infest rice crops in many regions of Japan. Males of each species were attracted to traps baited with conspecific, unmated females. Hexyl butyrate, $(E)$-2-hexenyl butyrate, and (E)-4-oxo-2-hexenal were identified as possible female-produced sex pheromone components for S. rubrovittatus, whereas hexyl hexanoate, $(E)$-2-hexenyl hexanoate, and octyl butyrate were found to be sex pheromone components for T. caelestialium. Pheromone doses and ratios were optimized for attraction of males of each species. Sticky traps set up close to or below the top of the plant canopy were optimal for monitoring these species, and trap catches were almost constant when traps were placed 7 or more meters in from the edge of a paddy field. Mixed lures, in which the six compounds from both species were loaded onto a single septum, or separate lures for each species, deployed in a single trap, were equally effective for monitoring both species simultaneously.

\section{Introduction}

The sorghum plant bug Stenotus rubrovittatus (Matsumura) (Figure 1(a)) and the rice leaf bug Trigonotylus caelestialium (Kirkaldy) (Heteroptera: Miridae) (Figure 1(b)) are major pests of rice, Oryza sativa L., in Japan [1]. They reproduce on graminaceous plants and invade rice fields after rice plant heading. Damage from bug feeding causes stained grains or kernel spotting, known as pecky rice (Figure 2) [2, 3]. Pecky rice contamination in brown rice, even in very small amounts (more than one stained grain per 1,000 brown rice grains), reduces rice quality under the Japanese rice quality regulations. This reduction in rice quality resulted in a price reduction to farmers of $8-16 \%$ in 2010 . Damage due to heteropteran bugs has occurred in $30 \%$ of rice cultivation areas in Japan since 1999, and the total area of rice fields requiring pecky rice control currently amounts to $1,700,000$ $1,900,000$ ha [1]. The range of S. rubrovittatus in Japan has been spreading since the 1990s [4], and this bug is now distributed from the southern part of Hokkaido to Kyushu
[1]. Trigonotylus caelestialium is found in most parts of eastern Japan, but its damage to rice occurs mainly in the northern part of Japan.

Sweeping of vegetation with an insect net is one of the conventional methods of surveying for insect pests in rice. However, this is a time- and labor-intensive method and requires some knowledge and experience to determine the types of insects captured. In contrast, pheromonebaited traps are easy to use and can provide similar data on seasonal population dynamics and densities of specific species. Species-specific pheromone traps also eliminate the need for specialized training to detect and identify the target insects.

Attractant pheromones have now been identified for three major true bug species that cause pecky rice in Japan: Leptocorisa chinensis Dallas (Heteroptera: Alydidae) [5] and the two mirid bugs which are the subject of this paper. Here, we summarize the identification of the sex pheromones for these two mirid species, and the testing of their pheromones for insect monitoring. 


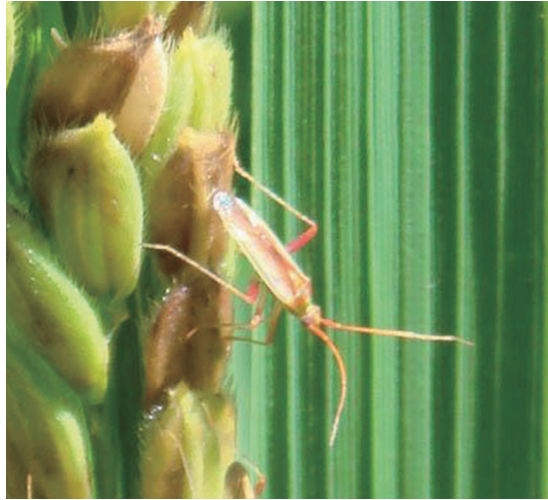

(a) Sorghum plant bug Stenotus rubrovittatus

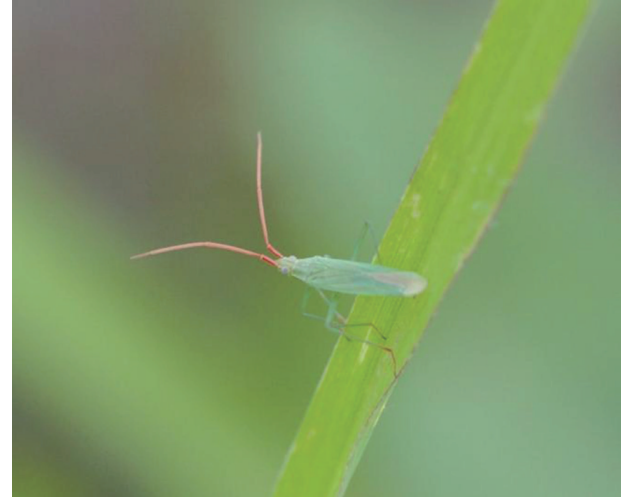

(b) Rice leaf bug Trigonotylus caelestialium

FIGURE 1: Sorghum plant bug Stenotus rubrovittatus (Matsumura) (a) and rice leaf bug Trigonotylus caelestialium (Kirkaldy) (b) (Heteroptera: Miridae).

\section{Sex Pheromones of the Mirid Bugs, Stenotus rubrovittatus, and Trigonotylus caelestialium}

2.1. Mate Attraction and Mating Behavior. In the true bug family Miridae, orientation of males to conspecific females has been observed in several species [6-12], including $T$. caelestialium [13] and S. rubrovittatus [14]. In T. caelestialium and S. rubrovittatus, males were attracted only to conspecific females, and females were not attracted by either sex $[13,14]$. These results indicated that females of these species probably produced female-specific sex attractant pheromones.

In S. rubrovittatus, courtship behavior by males consists of four steps: approaching a female, antennation (touching with the antennae), grasping (holding with the antennae), and mounting [15]. Male T. caelestialium exhibits similar behavioral steps, except for antennation [13]. In both species, calling behavior in females, as observed in another mirid bug, Campylomma verbasci [8], was not observed $[13,15]$.

\subsection{Identification of Sex Pheromone Components}

2.2.1. Stenotus rubrovittatus. Whole-body extracts of $S$. rubrovittatus females were attractive to conspecific males [16], and 16 peaks were detected from hexane extracts of whole female bodies by coupled gas chromatographymass spectrometry (GC-MS) analysis (Table 1) [16]. The three most abundant components elicited responses from antennae of male bugs in gas chromatographyelectroantennographic detection (GC-EAD) analyses (Figure 3) [17]. These three compounds were identified as hexyl butyrate, (E)-2-hexenyl butyrate, and (E)-4oxo-2-hexenal (Figure 4(a)). When the attractiveness of a $100: 40: 200(\mu \mathrm{g})$ combination of hexyl butyrate, $(E)$ 2-hexenyl butyrate, and (E)-4-oxo-2-hexenal and subsets thereof were examined, a few males were attracted to the binary blend of hexyl butyrate and (E)-2-hexenyl butyrate, and no males were attracted to lures lacking either hexyl butyrate or (E)-2-hexenlyl butyrate [18]. Significantly more

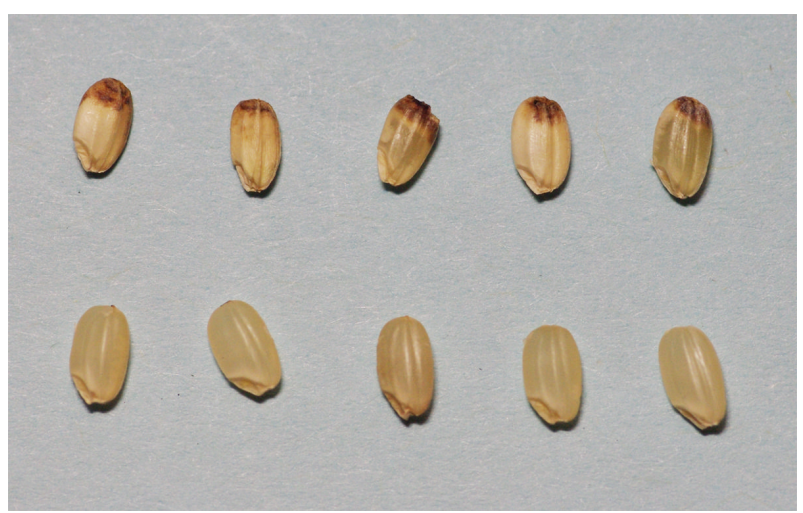

FIGURE 2: Damaged (pecky rice; top row) and nondamaged (bottom row) brown rice grains.

S. rubrovittatus males were caught in traps baited with the three-component blend $(P<0.05)$ than in unbaited controls [18]. Extracts of female S. rubrovittatus contained at least 13 minor components, but lures impregnated with female extracts were no more attractive to males than the three-component blend [16], and none of the minor components enhanced the attractiveness of the lure when added individually to the three-component blend. These results suggest that the minor components, in the amounts found in the extracts of females, are not part of the sex attractant pheromone [16].

2.2.2. Trigonotylus caelestialium. Whole-body hexane extracts of $T$. caelestialium females were not attractive to conspecific males [19], even though live females had been shown to attract males. This suggested that attraction of males to extracts was being masked by other components of the extracts. Thus, extracts were fractionated by liquid chromatography on Florisil, successively eluting with hexane and $5 \%, 15 \%, 25 \%$, and $50 \%$ ether in hexane. Ten components in the $5 \%$ ether in hexane fraction elicited responses from antennae of conspecific males in GC-EAD analyses [20]. 


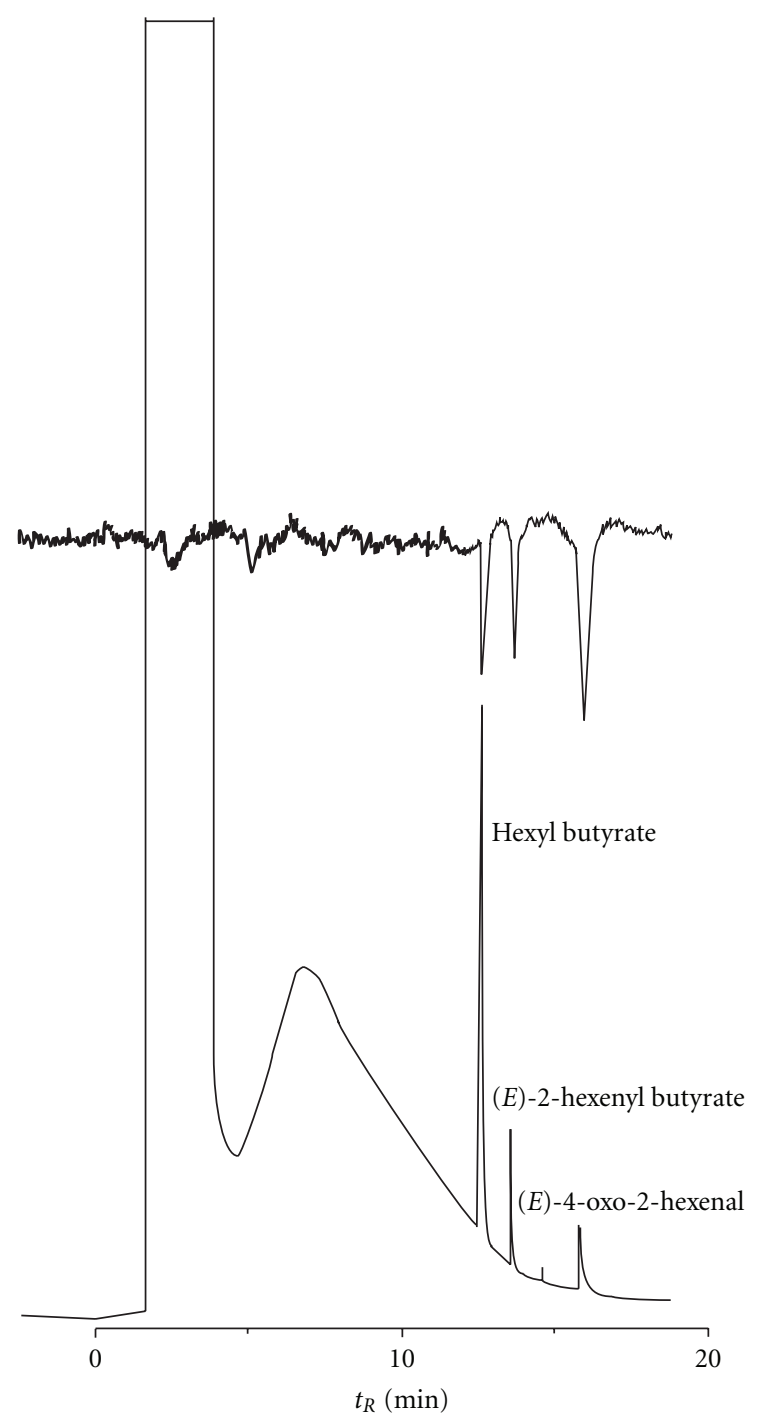

Figure 3: Coupled gas chromatography-electroantennographic detection (GC-EAD) chromatograms showing the responses from an antenna of a male Stenotus rubrovittatus (top trace) to a crude extract of unmated females.

Partial reconstruction of the mixture of EAD-active compounds determined that a six-component mixture of $5 \mu \mathrm{g}$ hexyl hexanoate, $2.5 \mu \mathrm{g}(E)$-2-hexenyl hexanoate, $5 \mathrm{ng}$ hexyl (E)-2-hexenoate, $150 \mathrm{ng}$ octyl butyrate, $275 \mathrm{ng}$ octyl hexanoate, and $275 \mathrm{ng}(E)$-2-octenyl hexanoate attracted males, whereas lures lacking either hexyl hexanoate or $(E)-2$ hexenyl hexanoate were not attractive [20]. Furthermore, a two-component blend of hexyl hexanoate and $(E)$-2-hexenyl hexanoate (Figure 4(b)) was attractive to males, and adding octyl butyrate (Figure 4(b)) enhanced the attraction [20].

2.3. Chemicals. The components identified as possible sex attractant pheromones of S. rubrovittatus [18] and T. caelestialium [20] are all commercially available in high purity, with the exception of (E)-4-oxo-2-hexenal. (E)-4-Oxo-2hexenal was obtained readily in one step from commercially
Table 1: Compounds identified in extracts of female Stenotus rubrovittatus [16].

\begin{tabular}{lccc}
\hline Compounds & KI $\mathrm{HPINNOWax}$ & $K_{\mathrm{HP1}}^{\mathrm{a}}$ & $\begin{array}{c}\text { Relative amount } \\
(\%)^{\mathrm{b}}\end{array}$ \\
\hline Hexyl acetate & 1,276 & 996 & 0.8 \\
Pentyl butyrate & 1,320 & 1,076 & 0.5 \\
$(E)$-2-Hexenyl acetate & 1,337 & 995 & 0.2 \\
Hexyl propionate & 1,342 & 1,091 & 0.2 \\
4-Methylpentyl butyrate & 1,374 & 1,142 & 0.8 \\
Hexyl butyrate & 1,417 & 1,192 & 100 \\
Hexyl isopentanoate & 1,447 & 1,228 & 0.2 \\
(E)-2-Hexenyl butyrate & 1,475 & 1,195 & 46.2 \\
(Z)-3-Hexenyl butyrate & 1,466 & 1,146 & 0.5 \\
Hexyl pentanoate & 1,516 & 1,274 & 0.2 \\
Heptyl butyrate & 1,520 & 1,276 & 0.1 \\
Hexyl (E)-2-butenoate & 1,562 & 1,224 & 0.1 \\
(E)-4-Oxo-2-hexenal & 1,599 & 958 & 5.4 \\
Hexyl hexanoate & 1,613 & 1,370 & 0.1 \\
Octyl butyrate & 1,620 & 1,374 & 0.1 \\
Methyl tetradecanoate & 2,014 & 1,684 & 2.0 \\
\hline
\end{tabular}

${ }^{a}$ Kováts retention index [22] using HP-INNOWax (KI $\left.\mathrm{I}_{\text {HPINNOWax }}\right)$ and HP-1 $\left(K \mathrm{I}_{\mathrm{HP} 1}\right)$ columns.

${ }^{b}$ Values are percentages relative to the amount of hexyl butyrate.

available 2-ethylfuran [21], in high chemical purity $(96.9 \%$ pure, as custom synthesized by Shin-Etsu Chemical Co., Ltd.). Although this compound is unstable in impure form, in our hands, pure (E)-4-oxo-2-hexenal was relatively stable in a freezer and could be used in a mixture of synthetic pheromones without further purification.

2.4. Lures. The rubber septa which are often used as pheromone dispensers for lepidopteran insects are not the most suitable pheromone dispensers for pheromones of some mirid bugs because most of the volatile pheromone components for mirid bugs are of relatively low molecular weight, and the components evaporate from septa too quickly. For example, for Phytocoris relativus and Phytocoris californicus, rubber septum lures that had been exposed in the field for 2 weeks were significantly less attractive than fresh lures $[23,24]$. For Lygus rugulipennis, the effective lifetime of a rubber septum lure loaded with the same pheromone compounds as those of S. rubrovittatus was only a few hours, whereas polyethylene vials or sachets were found to give sustained release for at least 2 weeks [25]. Nevertheless, because rubber septa are easy to work with, they can be used as dispensers for short-term experiments testing variables such as pheromone blend ratio.

Experiments were carried out with both $S$. rubrovittatus $[16,18]$ and $T$. caelestialium $[20,26]$ to determine the optimal doses and ratios of pheromone compounds required for male attraction. For $S$. rubrovittatus, using a rubber septum pheromone dispenser, the release rate of $(E)$-4-oxo2-hexenal from the lure was much faster than that of the butyrates [27]. Owing to the loss of significant quantities of 


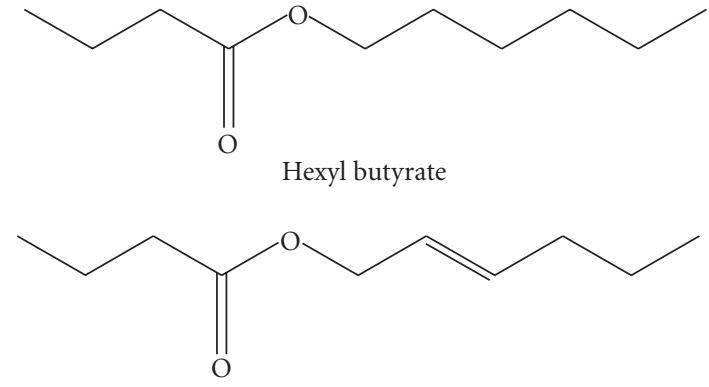

(E)-2-hexenyl butyrate

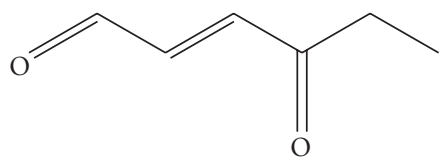

(E)-4-oxo-2-hexenal

(a) Sorghum plant bug Stenotus rubrovittatus

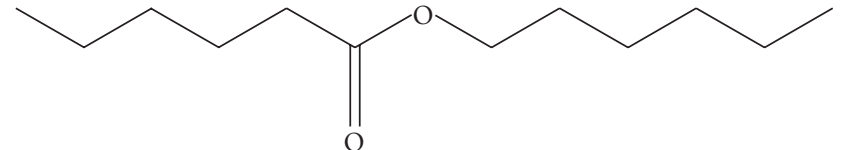

Hexyl hexanoate

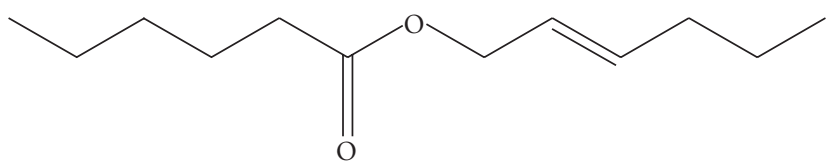

(E)-2-hexenyl hexanoate

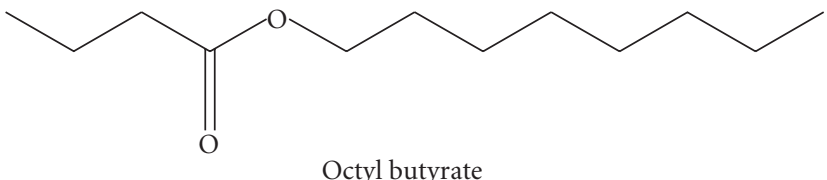

(b) Rice leaf bug Trigonotylus caelestialium

FIGURE 4: Structures of the pheromone components of Stenotus rubrovittatus (a) and Trigonotylus caelestialium (b).

(E)-4-oxo-2-hexenal during impregnation into the septum, the amount of (E)-4-oxo-2-hexenal released from the septum appeared to be substantially less than the amount that was loaded onto the septum. Thus, the ternary mixture formulated with the ratio found in the female extract (a $5: 2: 0.5$ blend of hexyl butyrate, (E)-2-hexenyl butyrate, and (E)-4-oxo-2-hexenal) was not attractive in preliminary bioassays, but ratios containing higher proportions of $(E)-4-$ oxo-2-hexenal than found in the female extracts were found to attract males in subsequent bioassays [16]. As a result, a $5: 1: 10$ blend of hexyl butyrate, $(E)$-2-hexenyl butyrate, and (E)-4-oxo-2-hexenal at a total dose of $64 \mu \mathrm{g}$ per septum was found to be most effective for attraction of males [16]. Analyses of the volatiles released from septa loaded with this blend showed that the ratio of compounds released from the lure was approximately $5: 1: 0.3$, substantially different than the $5: 1: 10$ loading rate.

Innocenzi et al. [27] observed that the release rate of $(E)$ 4-oxo-2-hexenal drastically decreased when this compound was mixed with hexyl butyrate. They suggested that this phenomenon might be caused by chemical interaction between hexyl butyrate and (E)-4-oxo-2-hexenal, so they suggested that the butyrates and (E)-4-oxo-2-hexenal should be applied separately [25]. However, an experiment with $S$. rubrovittatus comparing catches in traps baited with lures containing the three-component blend versus catches in traps baited with a lure loaded with the two butyrates and a separate lure loaded with (E)-4-oxo-2-hexenal revealed that mixing the butyrates and (E)-4-oxo-2-hexenal made no difference [18]. Although the reason for this discrepancy between experiments is not clear, it may have been influenced by the purity of the $(E)$-4-oxo-2-hexenal used in the two experiments.

Extracts from female T. caelestialium were found to contain hexyl hexanoate, $(E)$-2-hexenyl hexanoate, and octyl butyrate in a ratio of $1000: 414-491: 5-11$ [20]. Lures loaded with a $100: 40: 3$ ratio of hexyl hexanoate, (E)-2-hexenyl hexanoate, and octyl butyrate at $4.29-14.3 \mu \mathrm{g}$ per glass capillary tube ( $5 \mu \mathrm{L}, 0.021 \mathrm{~mm} \mathrm{ID}, 125 \mathrm{~mm}$ long) [20] or $10 \mu \mathrm{g}$ per rubber septum (gray sleeve stopper, $8 \mathrm{~mm}$ outside diameter) [26] were most effective for attraction of male $T$. caelestialium.

The effective lifetime of rubber septum lures for these two species (S. rubrovittatus, $14 \mathrm{~d}$ [16]; T. caelestialium $30 \mathrm{~d}$ [26]) was generally shorter than those of the rubber septum lures used for many Lepidoptera. Experiments with alternate dispensers are in progress, with the aim of developing lures with longer effective field lifetimes.

\section{Application of Synthetic Pheromone Lures for Monitoring Mirid Bug Populations}

As a possible alternative to sweep-net sampling of vegetation in and around paddy fields, we have been investigating the potential for using pheromone-baited traps for monitoring S. rubrovittatus and T. caelestialium. As expected, we found that the pheromone traps attracted only conspecific males, and not females or nymphs, nor did they attract significant numbers of nontarget insects.

3.1. Trap Design. Two types of pheromone traps, a water-pan trap and a double-sided sticky trap (Figure 5), were tested for capturing both mirid species. Possible effects of trap color have not yet been examined. The water pan trap consisted of a plastic pan $(\sim 40 \mathrm{~cm}$ diam $\times 12 \mathrm{~cm}$ deep $)$ filled with water, with a small amount of surfactant added to prevent trapped bugs from escaping. The lure was hung above the water on a wire frame. Double-sided sticky traps made up of two sticky boards $(24 \mathrm{~cm} \times 30 \mathrm{~cm})$ were hung vertically, with the lure placed at the top [28]. 


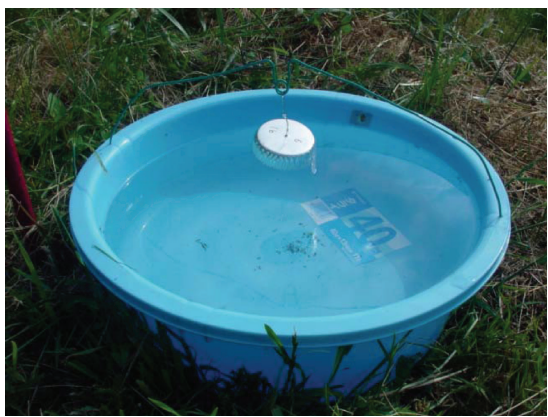

(a) Water pan trap

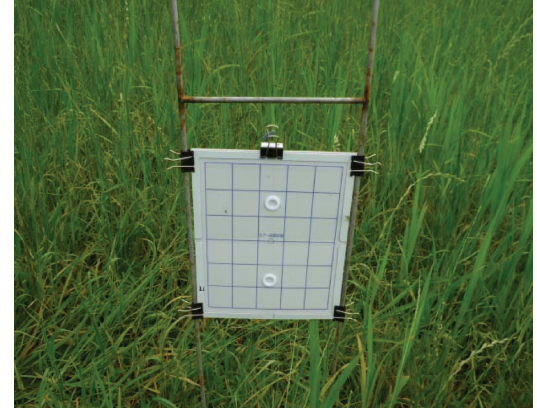

(b) Double-sided sticky trap

Figure 5: Typical water pan trap (a) and double-sided sticky trap (b) tested for catching mirid bugs.

For S. rubrovittatus, double-sided sticky traps were more effective in capturing males than water pan traps. Sticky traps caught an average of $2.1 \pm 0.4( \pm \mathrm{SE} ; n=12)$ males per trap over 4 days, whereas significantly fewer males $(0.8 \pm 0.3, n=$ 12 ; $t$-test, $P<0.01)$ were captured in water-pan traps during the same time period.

For T. caelestialium, there was no significant difference in the effectiveness of the water pan or sticky traps [29, 30]. Water pan traps are cheaper than sticky board traps, but this cost saving is negated by the need to replenish the water frequently, especially in hot and/or dry areas. Thus, for practical use, sticky traps may be more suitable for monitoring both species than water pan traps. However, to be most effective, sticky board traps need to be replaced weekly. In field experiments with $S$. rubrovittatus, significantly more $(2.4 \pm 0.9 ; n=12)$ males per trap were caught on new sticky traps than on sticky traps kept outdoors for 1 week before the experiments $(0.3 \pm 0.2$ males; $t$-test, $P=0.036)$.

3.2. Optimizing Trap Location. Sticky traps placed below or near the top of the plant canopy were more effective than traps placed $30 \mathrm{~cm}$ above the canopy, for both T. caelestialium [28] and S. rubrovittatus. However, traps set below the canopy picked up a large amount of leaf litter and other detritus, rendering them less effective and more difficult to count. The effects of trap height have also been evaluated with the mullein bug C. verbasci in apple orchards [31], where it was found that more males were captured with traps higher (at 2.5-m) than lower (1.5-m) in the canopy.

The effect of trap position within a paddy field was tested by placing traps $0,3,7,15$, or $25 \mathrm{~m}$ in from the edge of the field $(85 \mathrm{~m}$ long $\times 55 \mathrm{~m}$ wide). More males were captured in traps placed $3 \mathrm{~m}$ in from the edge of the field than in traps placed at the edge of the field. When the traps were set at or over $7 \mathrm{~m}$ in from the edge, the numbers of captured males were almost constant regardless of the distance from the edge [32]. Therefore, we recommend that monitoring traps be placed 7 or more meters in from the edge of a field.

3.3. Application for Monitoring the Seasonal Numbers of Bugs. We directly compared the effectiveness of pheromone

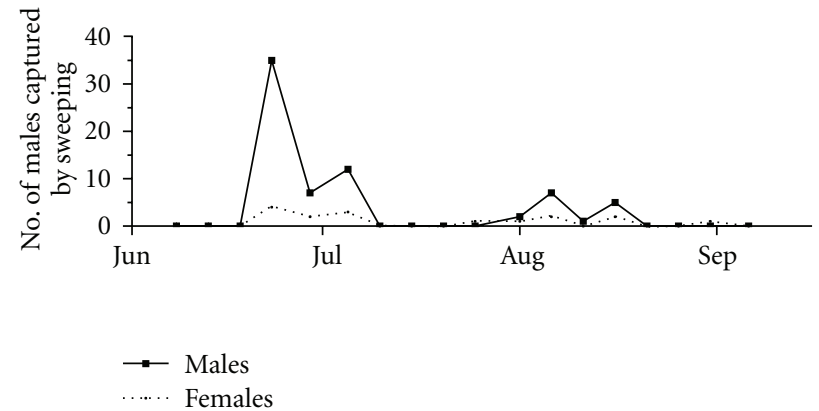

(a)

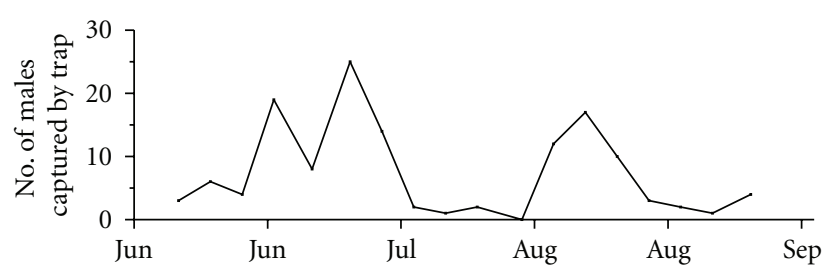

(b)

FIGURE 6: Comparison of the numbers of Trigonotylus caelestialium males caught by sweep-net sampling (a) or by a pheromone-baited sticky trap placed in the center of the paddy field (b). Sweep-net samples were taken 18 times at $5 \mathrm{~d}$ intervals. Data were modified from [28].

trapping versus sweep-net sampling for monitoring mirid bug populations. Thus, insects were sampled with a $36-\mathrm{cm}$ diameter sweep net, using 40 sweeps around a trap. For $T$. caelestialium, the number of adults captured by sweep-net sampling at 5-day intervals throughout the season increased from the middle of June to early or mid-July, then decreased, and increased again at the heading time of each rice variety. The seasonal trend of males caught in a trap set at the center of a paddy field ( $27 \mathrm{~m}$ long $\times 13 \mathrm{~m}$ wide) and the trend in the numbers of males captured by sweep-net sampling were similar (Figure 6) [28].

For S. rubrovittatus, catches in a trap set $10 \mathrm{~m}$ in from the edge of a paddy field ( $110 \mathrm{~m}$ long $\times 70 \mathrm{~m}$ wide) and 


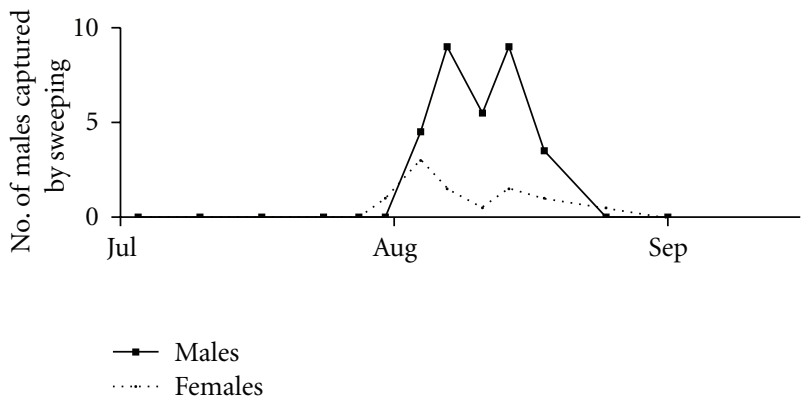

(a)

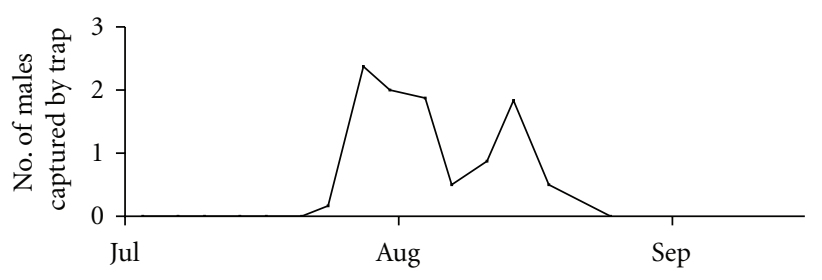

(b)

FIGURE 7: Comparison of the numbers of Stenotus rubrovittatus males caught by sweep-net sampling (a) or by a pheromone-baited sticky trap placed in the center of the paddy field (b). Sweep-net samples were taken 13 times at $7 \mathrm{~d}$ intervals. Data were modified from [32].

weekly sweep-net samples also showed similar seasonal patterns, with bugs being caught by both methods from about mid-July through late August (Figure 7) [32]. These results suggest that pheromone traps can be used as a tool for monitoring the seasonal population trends of these two mirid bugs in paddy fields.

Stenotus rubrovittatus and T. caelestialium are sympatric pests that infest rice crops in many regions of Japan. Synthetic pheromone lures for S. rubrovittatus do not attract T. caelestialium and vice versa. However, baiting traps with two separate lures (one for each species; combination lures) proved to be as effective as deploying separate traps for each species [33]. Even better, a mixed lure in which all six synthetic pheromone components (three from each species, see above) were loaded onto a single septum was as attractive to males of both species as the separate lures for each species, indicating no inhibition of attraction by any of the mixed pheromone components. These results suggest that mixed lures or combination lures can be used to monitor both species simultaneously, with a single trap. Furthermore, if necessary, S. rubrovittatus and T. caelestialium can be easily distinguished from each other by the color of the body and hind legs (Figure 1), even when stuck on sticky traps.

\section{Chemical Ecology of Mirid Bugs}

4.1. Acquisition of Pheromone Components. Crude pheromone extracts of mirid bugs can be prepared easily by brief soaking of individuals in a solvent such as hexane. However, the amounts recovered may be quite small, and, of course, the bugs are killed by the extraction process.
Thus, as an alternative, a method for sampling pheromone components from living organisms may be more useful for qualitative and/or quantitative analyses of insect-produced semiochemicals. Adsorbents such as Porapak Q, Tenax TA, or activated charcoal have been widely used for collection of volatiles from living organisms. In a recent innovation to this general method, magnetic stir bars coated with polydimethylsiloxane (Twister, Gerstel, Mülheim an der Ruhr, Germany; $1 \mathrm{~mm}$ film thickness $\times 10 \mathrm{~mm}$ length) have been used to adsorb headspace odors released by a variety of organisms [34]. The Twister was originally designed for solventless sample collection followed by thermal desorption and online analysis by GC or GC-MS. However, analytes also can be recovered from the Twister by extraction with small volumes of organic solvents. For S. rubrovittatus, pheromone components were collected on the Twister for $1 \mathrm{~d}$, followed by extraction in hexane (1 mL) [35]. Any desired number of replicate samples can be collected simultaneously by simply setting up the appropriate number of sampling chambers, each with its own Twister. Patterns of pheromone release from live individuals can be determined simply by changing the Twister at any desired time interval.

\subsection{Effect of Age and Mating Status of Females on Their Attrac-} tiveness. Males of $S$. rubrovittatus were more frequently attracted to young virgin females than to old virgin females and were rarely attracted to mated females [14], probably due to differences in the release rates of pheromone between the different classes of females. That is, mated females released less pheromone $(\sim 0.67 \mu \mathrm{g}$ in total) than unmated females $(\sim 1.54 \mu \mathrm{g})$, and young unmated females released more pheromone $(\sim 1.48 \mu \mathrm{g})$ than older unmated females $(\sim 0.79 \mu \mathrm{g})$ [35].

Interestingly, the amounts of volatile compounds released by females and the levels of compounds extracted from whole bodies with solvents did not appear to be correlated. The amounts of pheromone extracted from unmated females ( 3 -d old) totaled about $5 \mu \mathrm{g}$ and decreased with age to about $0.2 \mu \mathrm{g}$ extracted from 18 -d old females [35]. In contrast, the amount of pheromone extracted from mated females remained constant after mating until $18 \mathrm{~d}$ (total about 6-8 $\mu \mathrm{g}$ ) [35].

For T. caelestialium, there was no evidence for daily periodicity in male attraction to females or mating [36], whereas male $S$. rubrovittatus were most attracted to females at night and in the morning [37]. Mating behavior of $S$. rubrovittatus was observed at any time of day, and males courted females regardless of the time of day [37]. However, female mating receptivity was higher in the morning than in the afternoon [38]. For S. rubrovittatus, mating behavior was sometimes initiated even when attraction of males to females was not observed, suggesting that, over shorter ranges, other signals may mediate the initiation of copulation.

4.3. Pheromone-Based Control. The efficacy of pheromonebased mating disruption has been investigated with $C$. verbasci in Canada [31] and T. caelestialium in Japan [39]. Captures of male $C$. verbasci in pheromone-baited traps were 
greatly reduced when fields were treated with the complete, two-component sex pheromone blend, but reductions in trap captures were not observed when fields were treated with only one component of the pheromone [31]. In this experiment, decrease in trap captures was correlated with increased densities of pheromone dispensers.

In pheromone-based mating disruption experiments with the rice leaf bug $T$. caelestialium, treatment of grassy fields with pheromone-reduced captures of male T. caelestialium in traps baited with pheromone lures or with virgin females, and lowered population levels of T. caelestialium [39]. The total numbers of adults captured in the treated fields were $0-45 \%$ of those in the untreated fields, and the total numbers of nymphs sampled in the treated fields were $0-2.2 \%$ of those in the untreated fields [39].

However, T. caelestialium and $S$. rubrovittatus are polyphagous, and their host plant range includes a variety of graminaceous plants. Therefore, mated females of these species can invade treated areas from outside, even if mating behavior in treated areas such as paddy fields has been suppressed. Pecky rice damage results from mirid bugs invading paddy fields during the period when the rice ears are sprouting. The nymphs and adults present at the middle to end of the grain-filling period are the offspring of the adults that invaded early in the grain-filling period [39]. Decreasing the number of nymphs and adults during the grain-filling period should minimize pecky rice damage, and so pheromone-based control measures must remain effective for the duration of this period ( $\sim 2$ months). Furthermore, pheromone treatments are expensive $(\sim 9,300$ yen/ha for the compounds alone, at a rate of $60 \mathrm{~g} / \mathrm{ha}$ ) and must be reapplied approximately monthly [39]. Thus, under the conditions used in the present study, mating disruption of T. caelestialium is not economically feasible for preventing pecky rice damage. It remains to be determined whether largerscale application of mating disruption, and the resulting economies of scale, might make it possible to develop mating disruption of T. caelestialium and S. rubrovittatus as costeffective management tools.

\section{Conclusion}

Our results suggest that pheromone-baited traps for two mirid bugs, S. rubrovittatus and T. caelestialium, may be able to replace sweep-net sampling with monitoring seasonal population dynamics of these two important pests of rice, particularly as traps baited with mixed or combination lures can be used to sample both species simultaneously. Sticky traps set up near the top of the plant canopy, and 7 or more meters in from the edge of the paddy field were optimal for monitoring. For T. caelestialium, mating disruption experiments showed that although the pheromones interfered with male attraction to lures and to females and appeared to suppress populations, the costs of treatment and the relatively small decrease in damage to the rice crop suggest that mating disruption of this bug may not be a practical technique for preventing pecky rice damage.

\section{References}

[1] T. Watanabe and H. Higuchi, "Recent occurrence and problem of rice bugs," Plant Protection, vol. 60, pp. 201-203, 2006 (Japanese).

[2] H. Hayashi and K. Nakazawa, "Studies on the bionomics and control of the sorghum plant bug, Stenotus rubrovittatus Matsumura (Hemiptera: Miridae) 1. Habitat and seasonal prevalence in Hiroshima Prefecture," Bulletin of the Hiroshima Prefectural Agriculture Experimental Station, vol. 51, pp. 45-53, 1988.

[3] K. Ito, "The role of the feeding habits of Trigonotylus caelestialium (Kirkaldy) (Heteroptera: Miridae) on the production of pecky rice grains with special reference to the occurrence of split-hull paddy," Japanese Journal of Applied Entomology and Zoology, vol. 48, no. 1, pp. 23-32, 2004.

[4] H. Hayashi, "Historical changes and control of rice stink bug complex causing the pecky rice," Plant Protection, vol. 51, pp. 455-461, 1997 (Japanese).

[5] W. S. Leal, Y. Ueda, and M. Ono, "Attractant pheromone for male rice bug, Leptocorisa chinensis: semiochemicals produced by both male and female," Journal of Chemical Ecology, vol. 22, no. 8, pp. 1429-1437, 1996.

[6] A. L. Scales, "Female tarnished plant bugs attract males," Journal of Economic Entomology, vol. 61, pp. 1446-1447, 1968.

[7] F. E. Strong, J. A. Sheldable, P. R. Hughes, and E. M. K. Hussein, "Reproductive biology of Lygus hesperus Knight," Hilgardia, vol. 40, pp. 105-147, 1970.

[8] A. B. S. King, "Studies of sex attraction in the cocoa capsid, Distantiella theobroma (Heteroptera: Miridae)," Entomologia Experimentalis et Applicata, vol. 16, no. 2, pp. 243-254, 1973.

[9] G. Boivin and R. K. Stewart, "Attraction of male green apple bugs, Lygocoris communis (Hemiptera: Miridae), to caged females," Canadian Entomologist, vol. 114, pp. 765-766, 1982.

[10] H. M. A. Thistlewood, J. H. Borden, R. F. Smith, H. D. Pierce Jr., and R. D. McMullen, "Evidence for a sex pheromone in the mullein bug, Campylomma verbasci (Meyer) (Heteroptera: Miridae)," Canadian Entomologist, vol. 121, no. 9, pp. 737744, 1989.

[11] R. F. Smith and J. H. Borden, "Relationship between fall catches of Campylomma verbasci (Heteroptera: Miridae) in traps baited with females and density of nymphs in the spring," Journal of Economic Entomology, vol. 83, no. 4, pp. 1506-1509, 1990.

[12] R. F. Smith, S. O. Gaul, J. H. Borden, and H. D. Pierce Jr., "Evidence for sex pheromone in the apple brown bug, Atractotomus mali (Heteroptera: Miridae)," Canadian Entomologist, vol. 126, pp. 445-446, 1994.

[13] M. Kakizaki and H. Sugie, "Attraction of males to females in the rice leaf bug, Trigonotylus caelestialium (KIRKALDY) (Heteroptera: Miridae)," Applied Entomology and Zoology, vol. 32, no. 4, pp. 648-651, 1997.

[14] Y. Okutani-Akamatsu, T. Watanabe, and M. Azuma, "Mating attraction by Stenotus rubrovittatus (Heteroptera: Miridae) females and its relationship to ovarian development," Journal of Economic Entomology, vol. 100, no. 4, pp. 1276-1281, 2007.

[15] Y. Okutani-Akamatsu, T. Watanabe, and M. Azuma, "Mating behavior and oviposition of the sorghum plant bug, Stenotus rubrovittatus (Matsumura), (Heteroptera: Miridae)," Japanese Journal of Applied Entomology and Zoology, vol. 53, no. 1, pp. 13-20, 2009.

[16] T. Yasuda, K. Oku, H. Higuchi et al., "Optimization of blends of synthetic sex pheromone components for attraction of 
the sorghum plant bug Stenotus rubrovittatus (Matsumura) (Heteroptera: Miridae)," Applied Entomology and Zoology, vol. 44, no. 4, pp. 611-619, 2009.

[17] M. Ishizaki, "Female extract was injected. GC analyses were conducted on an Agilent $6890 \mathrm{~N}$ gas chromatograph equipped with a split/splitless injector and a flame ionization detector (FID). Helium was used as the carrier gas and initial flow was $1.0 \mathrm{ml} / \mathrm{min}$, the initial GC oven temperature was $50^{\circ} \mathrm{C}(2 \mathrm{~min}$ hold), increased to $240^{\circ} \mathrm{C}$ at $10^{\circ} \mathrm{C} / \mathrm{min}$, and then held for 5 min. An EAG response was obtained simultaneously with the FID recording" unpublished data.

[18] T. Yasuda, S. Shigehisa, K. Yuasa et al., "Sex attractant pheromone of the sorghum plant bug Stenotus rubrovittatus (Matsumura) (Heteroptera: Miridae)," Applied Entomology and Zoology, vol. 43, no. 2, pp. 219-226, 2008.

[19] M. Kakizaki, "Investigation of test methods for a sex pheromone of the rice leaf bug, Trigonotylus caelestialium (Kirkady) (Heteroptera: Miridae)," Annual Report of the Society of Plant Protection of North Japan, vol. 52, pp. 135-137, 2001.

[20] M. Kakizaki and H. Sugie, "Identification of female sex pheromone of the rice leaf bug, Trigonotylus caelestialium," Journal of Chemical Ecology, vol. 27, no. 12, pp. 2447-2458, 2001.

[21] J. A. Moreira and J. G. Millar, "Short and simple syntheses of 4-oxo-(E)-2-hexenal and homologs: pheromone components and defensive compounds of hemiptera," Journal of Chemical Ecology, vol. 31, no. 4, pp. 965-968, 2005.

[22] E. Kováts, "Gas chromatographic characterization of organic substances in the retention index system," Advances in Chromatography, vol. 1, pp. 229-247, 1965.

[23] J. G. Millar, R. E. Rice, and Q. Wang, "Sex pheromone of the mirid bug Phytocoris relativus," Journal of Chemical Ecology, vol. 23, no. 7, pp. 1743-1754, 1997.

[24] J. G. Millar and R. E. Rice, "Sex pheromone of the plant bug Phytocoris californicus (Heteroptera: Miridae)," Journal of Economic Entomology, vol. 91, no. 1, pp. 132-137, 1998.

[25] P. J. Innocenzi, D. R. Hall, J. V. Cross, and H. Hesketh, "Attraction of male European tarnished plant bug, Lygus rugulipennis to components of the female sex pheromone in the field," Journal of Chemical Ecology, vol. 31, no. 6, pp. 14011413, 2005.

[26] H. Higuchi, A. Takahashi, T. Fukumoto, and F. Mochizuki, "Attractiveness of synthetic sex pheromone of the rice leaf bug, Trigonotylus caelestialium (Kirkaldy) (Heteroptera: Miridae) to males," Japanese Journal of Applied Entomology and Zoology, vol. 48, no. 4, pp. 345-347, 2004.

[27] P. J. Innocenzi, D. R. Hall, J. V. Cross et al., "Investigation of long-range female sex pheromone of the European tarnished plant bug, Lygus rugulipennis: chemical, electrophysiological, and field studies," Journal of Chemical Ecology, vol. 30, no. 8, pp. 1509-1529, 2004.

[28] M. Ishimoto, H. Sato, Y. Muraoka et al., "Monitoring adult rice leaf bug, Trigonotylus caelestialium (Kirkaldy) (Heteroptera: Miridae), with a synthetic sex pheromone trap in paddy fields," Japanese Journal of Applied Entomology and Zoology, vol. 50, no. 4, pp. 311-318, 2006.

[29] M. Ishimoto, "Effect of trap types and height on male catches of the rice leaf bug, Trigonotylus caelestialium (Kirkaldy) (Heteroptera: Miridae), in a synthetic sex pheromone trap," Proceeding of the Association for Plant Protection of Hokuriku, vol. 54, pp. 13-17, 2005 (Japanese).
[30] M. Takita, "Examination of shape of synthetic sex pheromone trap in rice leaf bug, Trigonotylus caelestialium," Annual Report of the Society of Plant Protection of North Japan, vol. 56, pp. 108-110, 2005 (Japanese).

[31] H. L. Mcbrien, G. J. R. Judd, and J. H. Borden, "Potential for pheromone-based mating disruption of the mullein bug, Campylomma verbasci (Meyer) (Heteroptera: Miridae)," Canadian Entomologist, vol. 128, no. 6, pp. 1057-1064, 1996.

[32] A. Takeda, K. Oku, W. Sugeno et al., "Monitoring sorghum plant bug, Stenotus rubrovittatus (Matsumura) (Hemiptera: 4 Miridae), with a synthetic sex pheromone trap in paddy fields," Japanese Journal of Applied Entomology and Zoology, vol. 56, no. 1, pp. 26-29, 2012.

[33] T. Yasuda, K. Oku, H. Higuchi et al., "A multi-species pheromone lure: a blend of synthetic sex pheromone components for two mirid species, Stenotus rubrovittatus (Matsumura) and Trigonotylus caelestialium (Kirkaldy) (Heteroptera: Miridae)," Applied Entomology and Zoology, vol. 45, no. 4, pp. 593-599, 2010.

[34] C. Bicchi, C. Cordero, E. Liberto et al., "Dual-phase twisters: a new approach to headspace sorptive extraction and stir bar sorptive extraction," Journal of Chromatography A, vol. 1094, no. 1-2, pp. 9-16, 2005.

[35] K. Oku and T. Yasuda, "Effects of age and mating on female sex attractant pheromone levels in the sorghum plant bug, Stenotus rubrovittatus (Matsumura)," Journal of Chemical Ecology, vol. 36, no. 5, pp. 548-552, 2010.

[36] H. Higuchi, A. Takahashi, A. Nagasawa, M. Ishimoto, and M. Fukuyama, "Daily periodicity of sex pheromone emission and mating in the rice leaf bug, Trigonotylus caelestialium (Kirkaldy) (Heteroptera: Miridae)," Japanese Journal of Applied Entomology and Zoology, vol. 51, no. 1, pp. 51-54, 2007.

[37] T. Kichishima, M. Fukuyama, H. Higuchi, A. Takahashi, and A. Nagasawa, "Daily periodicity of attraction for males to females and mating in the sorghum plant bug, Stenotus rubrovittatus (matsumura)," Japanese Journal of Applied Entomology and Zoology, vol. 53, no. 2, pp. 57-59, 2009.

[38] K. Oku, Y. Okutani-Akamatsu, and T. Watanabe, "Effects of female age and ovarian development on mating behavior in Stenotus rubrovittatus (Heteroptera: Miridae)," Annals of the Entomological Society of America, vol. 103, no. 5, pp. 802-805, 2010.

[39] M. Kakizaki, “The sex pheromone components for mating disruption of the rice leaf bug, Trigonotylus caelestialium (Heteroptera: Miridae)," Applied Entomology and Zoology, vol. 39, no. 2, pp. 221-228, 2004. 

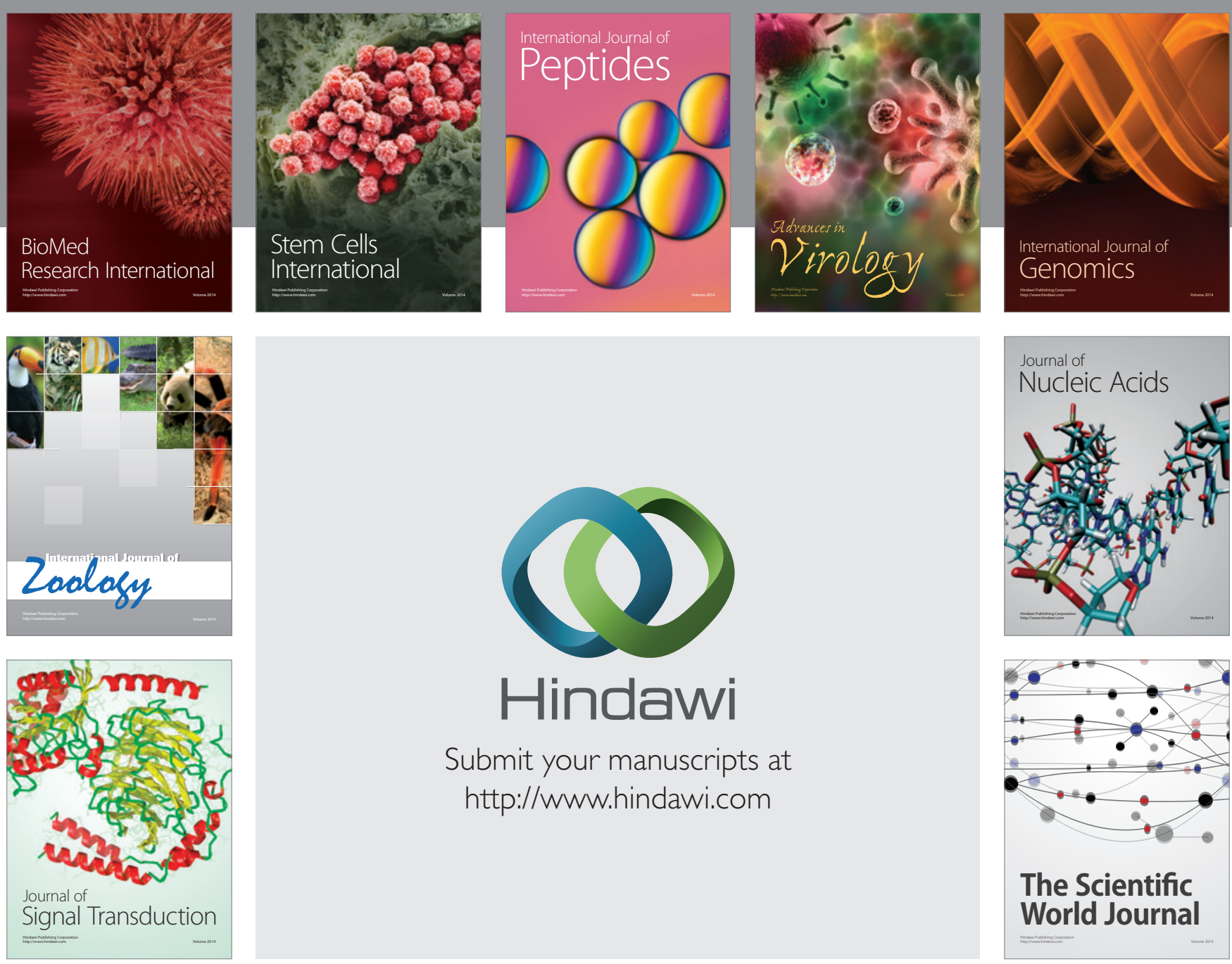

Submit your manuscripts at

http://www.hindawi.com
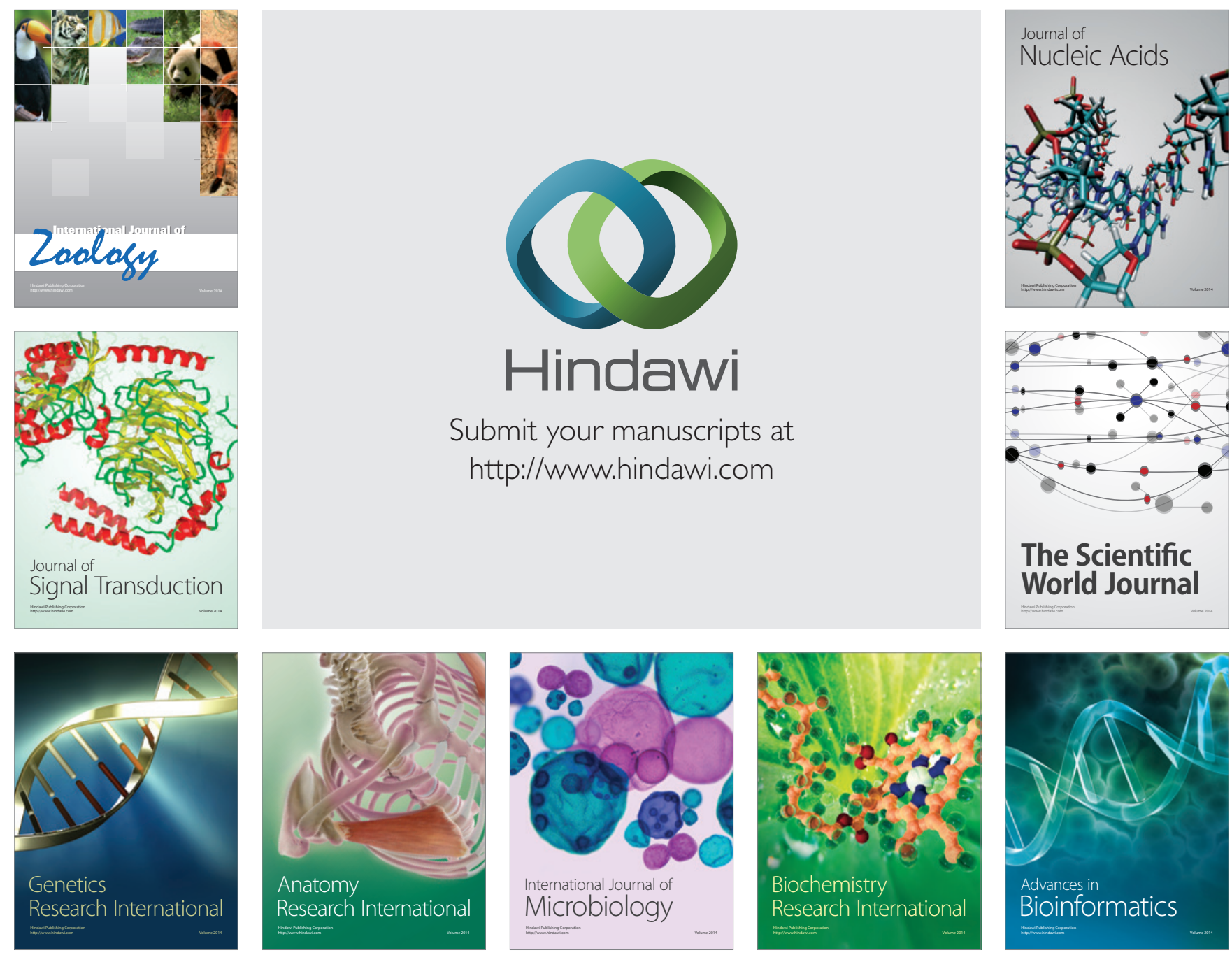

The Scientific World Journal
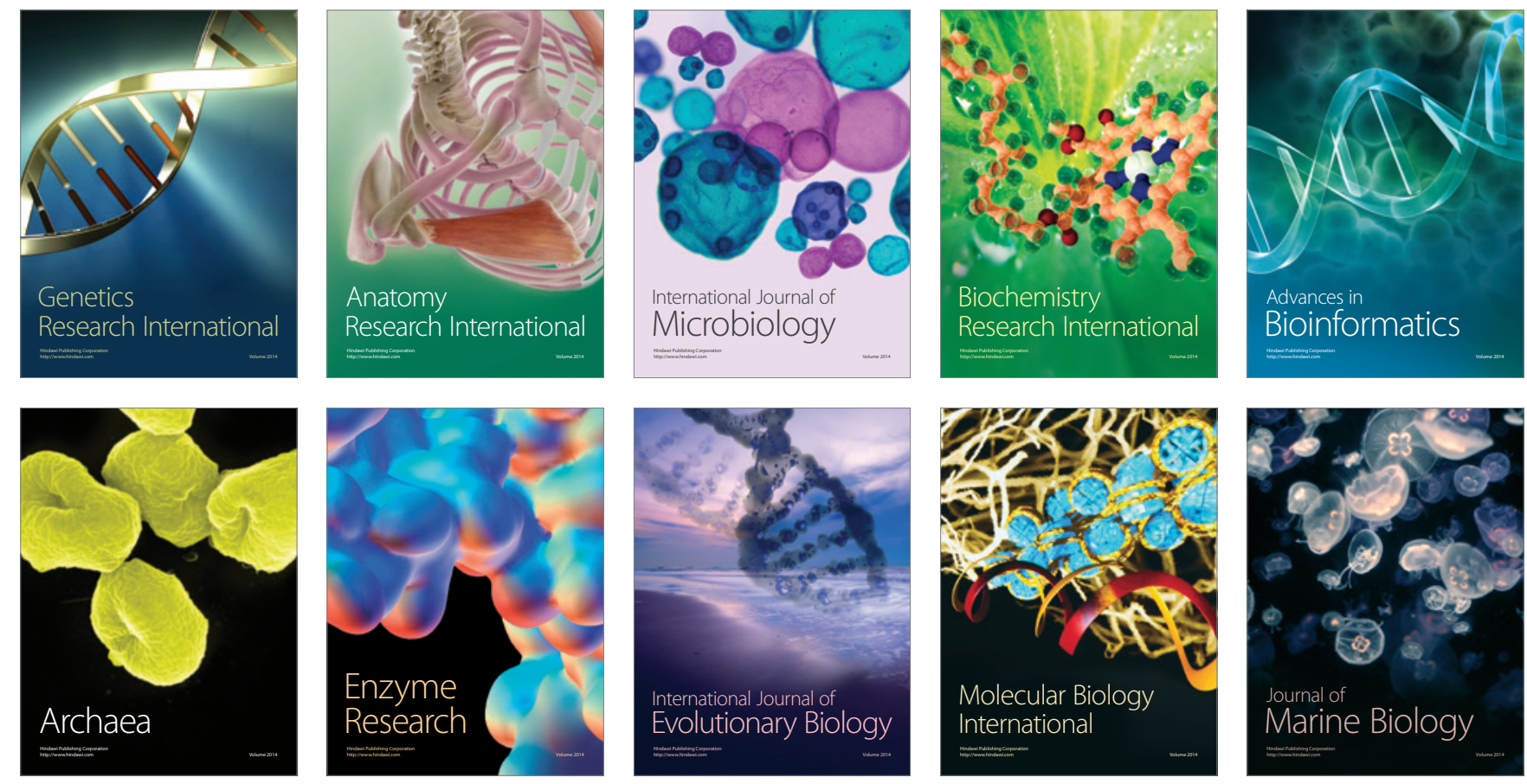